Tohok u J. exp. Med., 1973, 109, 69-75

\title{
The Effect of GT 1341, a New Steroid Anesthetic, on the Isolated Heart Muscle
}

\author{
NaOfumi IfatsukI \\ Department of Anesthesiology, Tohoku University School of \\ Medicine, Sendai
}

Iwatsuki, N. The Effect of CT 1341, a New Steroid Anesthetic, on the Isolated Hexrt Muscle. Tohoku J. exp. Med,, 1973, 109 (1), 69-75 — A direct inotropic effect of CT 1341, a new steroid intravenous anesthetic, upon the myocardium was studied in isolated heart muscles of dogs by measurements of force-velocity relation. CT 1341 at the concentrations over $0.139 \mathrm{ml} / 100 \mathrm{ml}$ caused a dose-dependent leftward shift of the force-velocity curve. The maximum velocity of muscle shortening at zero load (Vmax) was decreased progressively with increasing concentration of CT 1341. The values of Vmax at the concentrations of $0.139 \mathrm{ml} / 100 \mathrm{ml}, 0.279 \mathrm{mg} / 100 \mathrm{ml}$ and $0.556 \mathrm{ml} / 100 \mathrm{ml}$ were $94.2 \%, 86.5 \%$ and $67.9 \%$ of the control, respectively. Peak force, maximum rate of force development and time to peak force during isometric contraction also showed a dose-dependent decrease. Isotonic net shortening, power and work on the heart muscle were decreased dose-dependently at any given load levels. These results suggest that CT 1341 exerts a direct negative inotropic effect on the myocardium. However, the values of $V \max$ were $98.6 \%$ and $94.2 \%$ of the control at the concentrations of $0.056 \mathrm{ml} / 100 \mathrm{ml}$ and $0.139 \mathrm{ml} / 100 \mathrm{ml}$, which were considered approximately to be the range of blood concentration at the clinically recommended induction doses $(0.04-0.1 \mathrm{ml} / \mathrm{kg})$. Therefore, the negative inotropic effect of CT 1341 upon the myocardium seems to be minor when it is used within the range of these doses. CT 134l; steroid anesthetic; isolated heart muscle; force-velocity relation; inotropism

CT 1341 is a new intravenous anesthetic agent which is a mixture of two steroids dissolved in cremophore EL. The injection is formulated as follows:

Steroid I

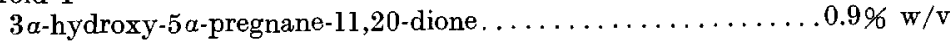

Steroid II

21-acetoxy-3 $\alpha$-hydroxy-5a-pregnane-11,20-dione $\ldots \ldots \ldots 0.3 \% \mathrm{w} / \mathrm{v}$

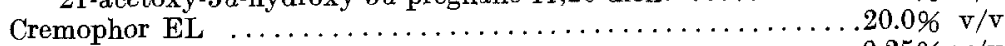

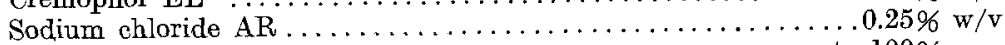

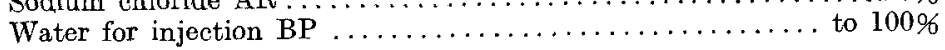<smiles>CC(=O)C1CCC2C1CC(=O)C1C2CCC2C[C@@H](O)CCC21C</smiles>

Steroid I

3a-hydroxy-5a-pregnane11,20 -dione<smiles>CC(=O)CC(=O)C1CCC2C3CCC4C[C@@H](O)CCC4(C)C3C(=O)CC12C</smiles>

Steroid II 21-acetoxy-3a-hydroxy $5 \alpha$-pregnane-11,20-dione

Received for publication, June 28, 1972.

* Director: Prof. K. Iwatsuki. 
Preliminary studies have indicated that CT 1341 is a promising intravenous anesthetic agent characterized by immediate induction of anesthesia of short duration, and rapid and uncomplicated recovery from anesthesia (Child et al. 1971; Campbell et al. 1971; Clarke et al. 1971; Savege et al. 1971; Swerdlow et al. 1971). In regard to cardiovascular effects, Campbell et al. (1971) reported a slight fall in blood pressure and stroke volume and a significant rise in heart rate with minimal changes in cardiac output. Savege et al. (1971) also reported a well-sustained cardiac output associated with a considerable fall in systolic blood pressure and increase in heart rate. An investigation of a direct effect of this agent on the contractility of the myocardium is considered to be significant to evaluate its effect on cardiac function.

A hyperbolic relation between the velocity of shortening and the force development of cardiac muscle has been described to provide a precise means for quantifying the mechanical behavior of the myocardium (Sonnenblick 1962). The present study is, therefore, undertaken to evaluate the effect of CT 1341 on the contractility of the myocardium by measurements of the force-velocity relation in isolated heart muscles.

\section{Materialis and Methods}

Trabeculae were excised rapidly from the right ventricles of dogs anesthetized with intravenous pentobarbital sodium $(25 \mathrm{mg} / \mathrm{kg})$. The muscle was suspanded in KrebsHenseleit solution kept at $27^{\circ} \mathrm{C}$ by a surrounded thermo-bath. The composition of this solution was as follows: $\mathrm{NaCl} 118, \mathrm{KCl} 4.7, \mathrm{CaCl}_{2} 2.5, \mathrm{MgSO}_{4} 1.2, \mathrm{NaHCO}_{3} 21, \mathrm{KH}_{2} \mathrm{PO}_{4}$ 1.2 and glucose $5.6 \mathrm{mM} /$ liter. The muscle was oxygenated by bubbling a $95 \% \mathrm{O}_{2}-5 \% \mathrm{CO}_{2}$ gas mixture in the bathing solution. Electrical stimulation was applied by means of mass electrodes placed parallel to the muscle at a frequency of $18 / \mathrm{min}$. The voltage was maintained 15-20\% above threshold (Nihon Kohden MSE-3). One end of the muscle was connected to a force transducer (Nihon Kohden SB-IT) and the other end was attached to the tip of a longer side of the isotonic lever system by a steel wire. A displacement transducer (Samborn Model 7DCDT-050) was arranged on a shorter side of the lever (Fig. 1). A load to the muscle was applied by hanging a weight on a shorter side of the lever. The initial muscle length was determined by applying a small load $(0.4 \mathrm{~g}$-preload). The muscle was then fixed at this length by a micrometer arranged at the tip of a longer side of the lever, so that the muscle was not elongated by adding loads (after-loads) during force-velocity measurements. The force-velocity relation was obtained by mearsuring peak velocity of muscle shortening when the after-loads were increased progressively from zero to isometric force. The velocity of shortening was computed by a RC-differentiator (time constant: $0.6 \mathrm{msec}$ ). The initial muscle length was measured with a telescope (Pika PPM-2) placed in front of the muscle bath.

The concentrations of CT $134 \mathrm{l}$ used in the experiments were $0.056 \mathrm{ml}, 0.139 \mathrm{ml}, 0.278$ $\mathrm{ml}$ and $0.556 \mathrm{ml}$ per $100 \mathrm{ml}$, and the measurement at each concentration was done 15 minutes after the administration of the agent directly to the bathing solution $(180 \mathrm{ml})$.

Recordings of shortening, velocity of shortening, force as well as stimuli were made with a direct-writing recorder (Nihon Kohden WI-260-M). The maximum velocity of shortening at zero load ( $\operatorname{Vmax}$ ) was obtained by extrapolating the force-velocity curve to the vertical axis. The maximum rate of isometric force development $(\max \mathrm{dF} / \mathrm{dt}$ ) was obtained from a tangent line on the isometric force-time curve. Each heart muscle served as its own control. Values were expressed as mean \pm SE and analyzed statistically by Fisher's t-test for paired data. 


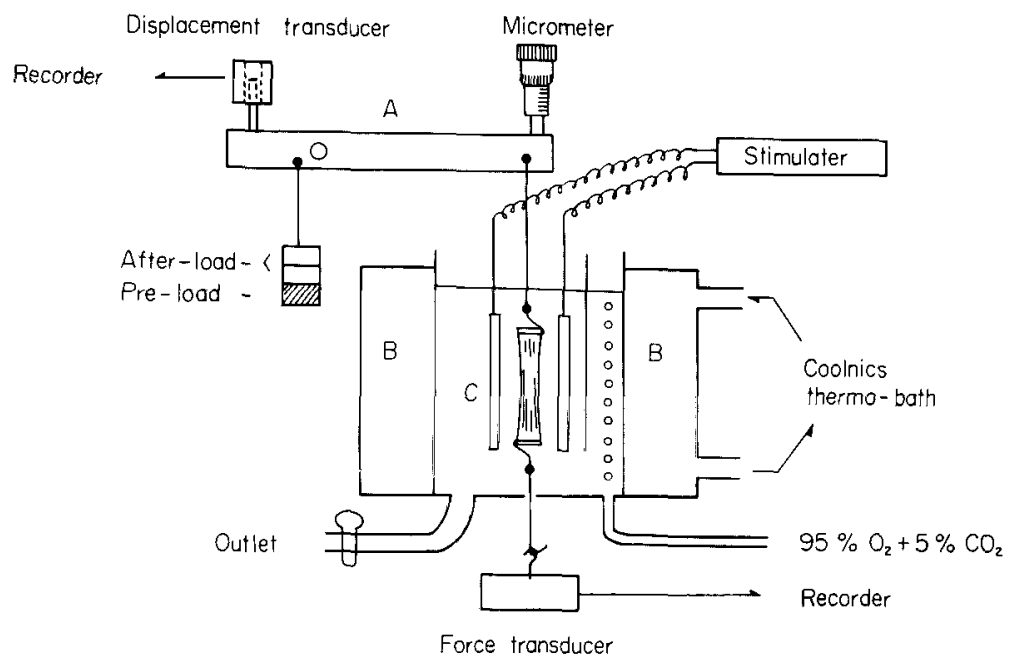

Fig. 1. A schematic diagram of setup for the study.

A: isotonic lever. B: thermo-bath. C: platinum mass electrode.

\section{RESULTS}

Four experiments were performed in each series. Muscle length, blotted weight and cross-sectional area of four trabeculae were $6.30 \pm 0.25 \mathrm{~mm}, 17.1 \pm 1.5$ $\mathrm{mg}$ and $2.72 \pm 0.24 \mathrm{~mm}^{2}$ (mean $\pm \mathrm{sE}$ ), respectively.

Force-velocity curves were shifted to the left in all four experiments when the heart muscles were exposed to CT 1341 at the concentrations over $0.139 \mathrm{ml} /$ $100 \mathrm{ml}$. The degree of leftward shift was dose-dependent (Fig. 2). Consequently, the maximum velocity of shortening at zero load $(V \max )$ and the isometric peak force $(\mathrm{F})$ also showed a dose-dependent decrease (Fig. 3). The percentage values to the control at the concentrations of $0.056,0.139$ and $0.278 \mathrm{ml} / 100 \mathrm{ml}$ were $98.6 \pm$ $1.0(0.3>\mathrm{p}>0.2), 94.2 \pm 2.4(0.05>\mathrm{p}>0.01)$ and $86.5 \pm 0.7(0.001>\mathrm{p})$ in $V \max$ and $95.0 \pm 1.6(0.1>p>0.05), \quad 79.8 \pm 2.0 \quad(0.01>p>0.001)$ and $62.8 \pm 3.7 \quad(0.001>$ p) in $\mathrm{F}$, respectively. In one experiment performed at a concentration of 0.556 $\mathrm{ml} / 100 \mathrm{ml}$, the percent value of $V \max$ was 67.9 and that of $\mathrm{F}$ was 34.8 of the control. There were concomitant decreases in shortening, power and work at any given load levels under the influence of CT 1341 in all four experiments (Fig. 4). The maximum rate of force development ( $\max \mathrm{dF} / \mathrm{dt}$ ) was also decreased progressively with increasing the concentration. The percentage values of $\max$ $\mathrm{dF} / \mathrm{dt}$ to the control at the concentrations of $0.056,0.139,0.278$ and $0.556 \mathrm{ml} / 100$ $\mathrm{ml}$ of $\mathrm{CT} 1341$ were $92.2 \pm 4.3(0.2>\mathrm{p}>0.1), 71.6 \pm 2.9(0.01>\mathrm{p}>0.001), 52.7 \pm$ $3.6(0.001>p)$ and 27.5 (one experiment), respectively (Fig. 5). The time to peak force from the onset of force development (TPF) were shortened by increasing the concentration of CT 1341 (Fig. 5). 


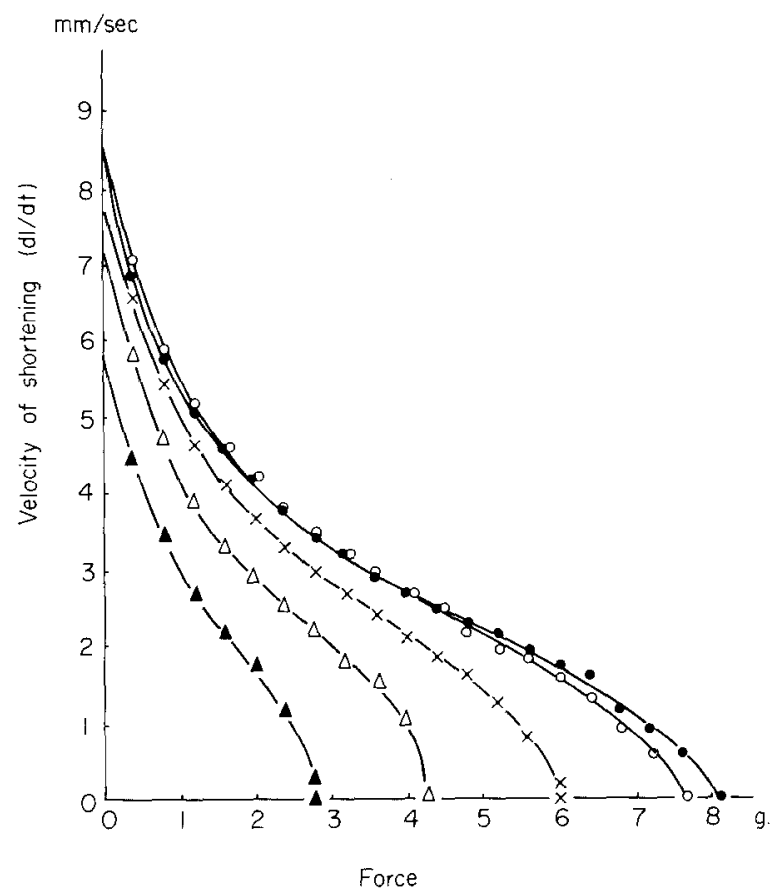

Fig. 2. Force-velocity curves under various concentrations of CT 1341. Abscissa: force (load) in $\mathrm{g}$. Ordinate: velocity of shortening ( $\mathrm{dl} / \mathrm{dt}$ ) in $\mathrm{mm} / \mathrm{sec}$. Curves are extended to the velocity axis to show the maximum velocity of shortening at zero load (Vmax). Initial muscle length $5.85 \mathrm{~mm}$, cross-sectional area $2.58 \mathrm{~mm}^{2}$. - Control,

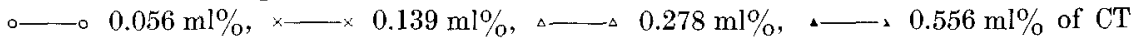
1341.
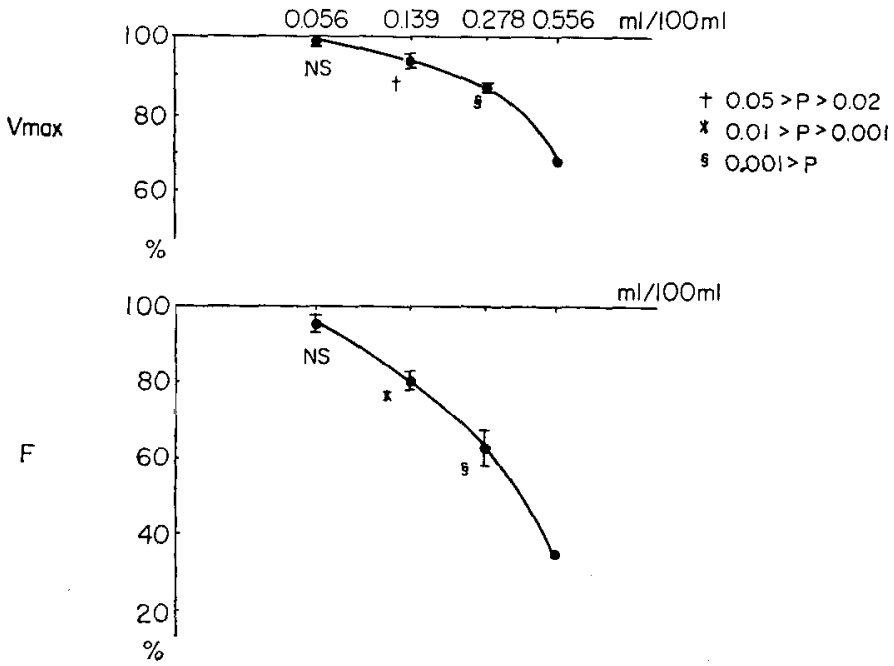

Fig. 3. Dose-response relations of the maximum velocity of shortening (Vmax) and isometric peak force (F). Abscissa: concentrations of CT 1341 in $\mathrm{ml}$ per $100 \mathrm{ml}$ of Krebs-Henseleit solution. Ordinate: mean per cent values $\pm S E$ to the control in $V \max$ (upper) and in $\mathrm{F}$ (lower). 

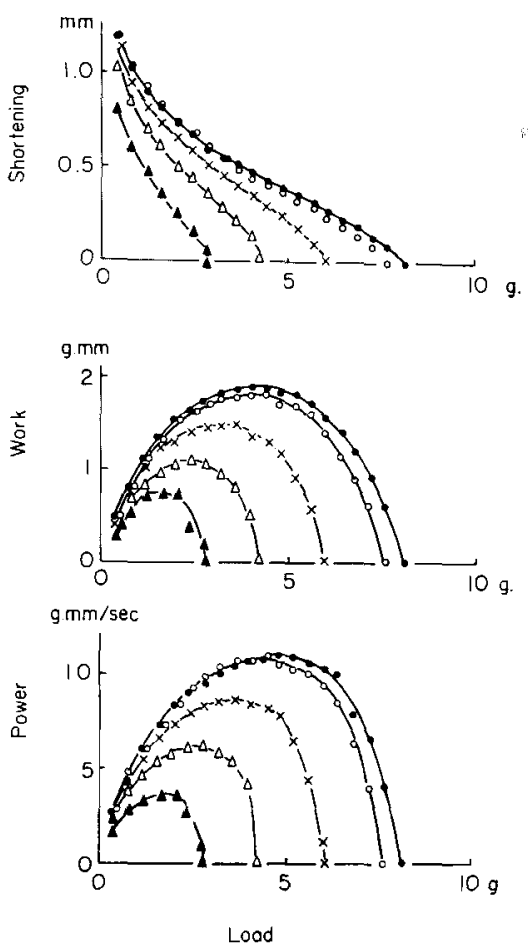

Fig. 4. The effects of CT 1341 on shortening, work and power. Data are derived from the experiment shown in Fig. 2. Note: dose-dependent decreases are seen in shortening, work and power at any given load levels during the administration of CT 1341. - C Control, ○— $0.056 \mathrm{ml} \%, \times — \times 0.139 \mathrm{ml} \%, \triangle \longrightarrow 0.278 \mathrm{ml} \%, \leadsto 0.556$ $\mathrm{ml} \%$ of $\mathrm{CT} 1341$.
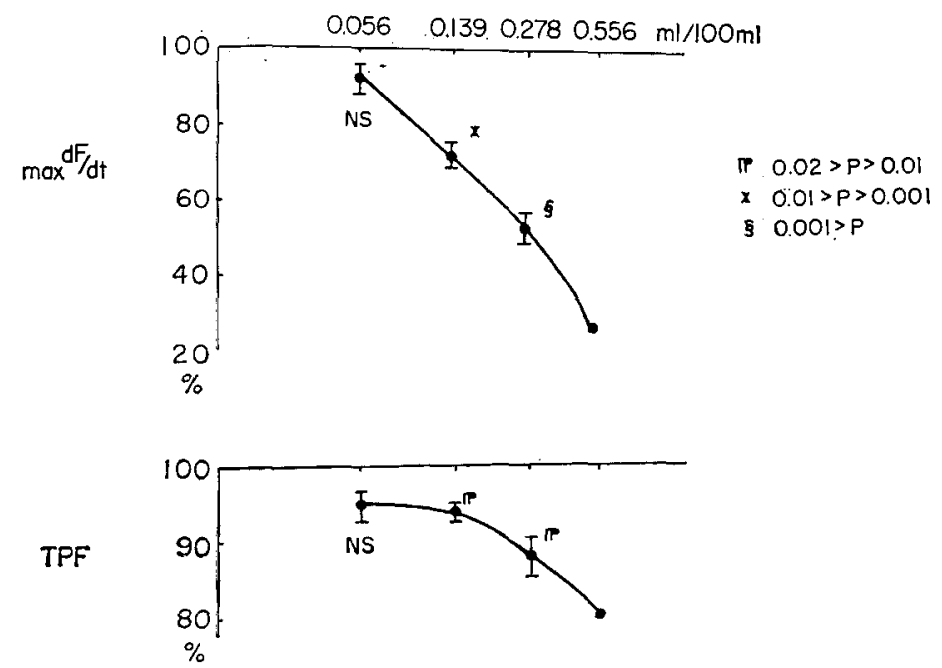

Fig. 5. Relations of the concentrations of CT $1341 \mathrm{in} \mathrm{ml} / 100 \mathrm{ml}$ (abscissa) to the changes in maximum rate of force development $(\max \mathrm{dF} / \mathrm{dt}$ ) and time to peak force (TPF) in percentage to the control (ordinate). 


\section{Discussion}

The force-velocity relations of cardiac muscle have been reported to provide a quantitative means of describing the mechanical performance of the myocardium and Vmax is particularly sensitive as an index of contractile state of the myocardium (Sonnenblick 1962). A leftward shift of the force-velocity curve and a decrease in Vmax produced by CT 1341 in the present study, therefore, clearly indicate that CT 1341 exerts a direct negative inotropic effect on the contractile state of cardiac muscle. A depressed contractile state was also evidenced by a decreased ability of cardiac muscle to shorten and to develop work and power at any given loading conditions. Another interesting finding in the present study is that a reduction of isometric force $(F)$ was accompanied by both decreases in the maximum rate of force development $(\max \mathrm{dF} / \mathrm{dt})$ and the time to peak force (TPF). Sonnenblick (1967) has suggested that the changes in $\max \mathrm{dF} / \mathrm{dt}$ reflect the intensity of the active state which is related to the rate of chemical processes, and the changes in TPF are proportional to the duration of the active state which indicates how long the chemical processes persist during muscle contraction. Therefore, the present study suggests that CT 1341 may cause changes in both the rate and the duration of chemical processes within the contractile site.

As the active substances of CT 1341 are dissolved in cremophore EL, there is a possibility that the solvent may play a part in the negative inotropic effect of the agent. In the present study, however, the administration of cremophor EL did not cause any changes in the force--velocity curve (Fig. 6). Therefore, the effect of CT 1341 on the cardiac muscle is considered to be due to the active substances themselves, but not due to the solvent.

The optimum doses of CT 1341 for the induction of anesthesia in man have been reported to be $0.04-0.1 \mathrm{ml}$ per kilogram of body weight (Clarke et al. 1971).

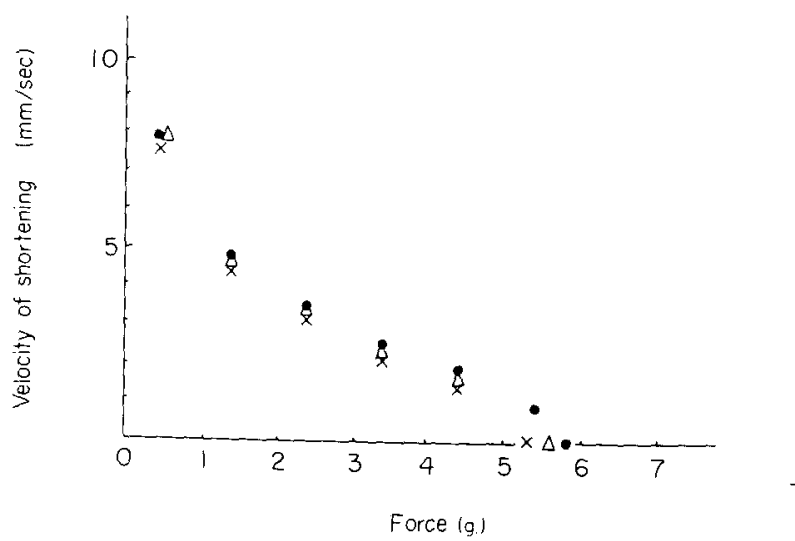

Fig. 6. The effect of cremophor EL on force-velocity curve. Note: The force-velocity curve under the influence of cremophor EL does not differ from that of the control. The concentrations of cremophor EL are the same as those ued in the study of CT 1341 . Initial muscle length $7.22 \mathrm{~mm}$, and cross-sectional area $1.13 \mathrm{~mm}^{2}$. .-.-Control, $\triangle 0.139 \mathrm{ml} \%, \ldots 0.278 \mathrm{ml} \%$, of cremophor EL. 
The blood concentrations at these doses are calculated to be 0.056 and $0.139 \mathrm{ml} /$ $100 \mathrm{ml}$ when blood volume is estimated to be $75 \mathrm{ml}$ per kilogram of body weight. Since Vmax was unchanged by $0.056 \mathrm{ml} / 100 \mathrm{ml}$ and slightly decreased by 0.139 $\mathrm{ml} / 100 \mathrm{ml}$ in the present study, it may be reasonable to state that a direct depressive effect of CT 1341 on the myocardium is minor when it is used within the range of these doses. However, as depressions in $\mathrm{F}$ and $\mathrm{dF} / \mathrm{dt}$ during isometric contraction were greater than that in $V \max$ during isotonic contraction, the depressive effect of CT 1341 on the myocardium may become more prominent in patients with the higher after-loaded heart such as arteriosclerosis.

\section{References}

1) Campbell, D., Forrester, A.C., Miller, D.C., Hutton, I., Kennedy, J.A., Lawrie, T.D.V., Lorimer, A.R. \& McCall, D. (1971) A preliminary clinical study of CT 1341 - A steroid anaesthetic agent. Brit. J. Anxesth., 43, 14-24.

2) Child, K.J., Currie, J.P., Davis, S., Dodds, M.G., Pearce, D.R. \& Twissell, D.J. (1971) The pharmacological properties in animals of CT 1341 - A new steroid anaesthetic agent. Brit. J. Anaesth.. 43, 2-13.

3) Clarke, R.S.J., Montogomery, S.J., Dundee, J.W. \& Bovill, J.G. (1971) Clinical studies of induction agents XXXIX: CT 1341, a new steroid anaesthetic. Brit. J. Anasth., 43, 947-952.

4) Savege, T.M., Foley, E.I., Coultas, R.J., Walton, B., Strunin, L., Simpson, B.R. \& Scott, D.F. (1971) CT 1341: Some effects in man - cardiorespiratory, electroencephalographic and biochemical measurements. Anxesthesia, 26, 402-413.

5) Sonnenblick, E.H. (1962) Implications of muscle mechanics in the heart. Fed. Proc. 21, 975-990.

6) Sonnenblick, E.H. (1967) Active state in heart muscle: Its delayed onset and modification by inotropic agents. J. gen. Physial., 50, 661-676.

7) Swerdlow, M., Chakraborty, S.K. \& Zahangir, M.A.H.M. (1971) A trial of CT 1341. Brit. J. Anaesth., 43, $1075-1080$. 